\title{
The Short-Term Effects of COVID-19 Pandemic Lockdown on Eating Habits and Dietary Changes Case of Tirana, Albania
}

\author{
Pranvera Troka, M.Sc \\ Assistant-Lecturer, Faculty of Economy and Agribusiness, \\ Agricultural University of Tirana, Albania \\ Prof. Assoc. Ilir Kapaj \\ Lecturer, Faculty of Economy and Agribusiness, \\ Agricultural University of Tirana, Albania \\ Ermelinda Satka, M.Sc \\ Assistant-Lecturer, Faculty of Economy and Agribusiness, \\ Agricultural University of Tirana, Albania
}

Doi:10.19044/esj.2021.v17n17p30

Submitted: 23 December 2020

Accepted: 19 March 2021

Published: 31 May 2021
Copyright 2021 Author(s)

Under Creative Commons BY-NC-ND

4.0 OPEN ACCESS

Cite As:

Troka P., Kapaj I. \& Satka E. (2021). The Short-Term Effects of COVID-19 Pandemic Lockdown on Eating Habits and Dietary Changes. Case of Tirana, Albania. European Scientific Journal, ESJ, 17(17), 30. https://doi.org/10.19044/esj.2021.v17n17p30

Abstract

Covid-19, one of the biggest crises that humanity has faced since WW2, has affected the normal life drastically and irreversibly. The rapid spread of the virus, radically changed every aspect of life, starting from the daily routine, the way of thinking and behaving, shopping habits and obviously eating habits and diets. This study aims to assess and analyze the short-term impact of quarantine on eating habits and food choices of citizens of Tirana, Albania, identifying and comparing the differences of quantity and quality of the main food products consumed during and after the lockdown. The research methodology used in this study is descriptive analysis. The selected area for the study is the city of Tirana, and the survey is conducted online due to the strict government regulations regarding social distancing and limited travelling after the Covid-19 outbreak. A total number of 325 respondents are included in the study. Based on the survey, $66.5 \%$ of the respondent's claimed that their diet was affected by the quarantine, while 
$33.5 \%$ have not experienced any major changes in their diets during the pandemic period. Staying at home has led $57 \%$ of them to consume all the main meals, and about $67.4 \%$ of the respondents claimed to have consumed more snacks than usually. The main products taken into study are bread, dairy, meat, fruits, vegetables, sweets, carbonated drinks, coffee, alcohol and water. Almost $50 \%$ of the respondents from a total of 325 confirmed that they consumed more bread, dairy products, meat, sweets and vegetables during the lockdown, than before. Their preferable foods were white bread, milk, chicken, homemade baked sweets and tomatoes. More than $70 \%$ claimed to have consumed more fruits, especially oranges, and more coffee and water. On the other hand, almost $70 \%$ of the respondents were drinking less alcohol and carbonated drinks during lockdown than before.

Keywords: Covid-19, lockdown, eating habits, dietary changes, consumer behavior

\section{Introduction}

On March 8, 2020, Albania confirmed the first two cases of Coronavirus, a father and a son, who had come to the country from Florence, Italy. On the same day, the government banned all flights and ferries coming from the northern part of Italy until $3^{\text {rd }}$ of April 2020. (Health Ministry of Albania, n.d.).

The government also closed schools, ordered a ban on all groups of people, and asked sports federations to suspend all activities. The quarantine lasted for about two months until the country began to reopen gradually.

The word quarantine comes from the Italian 'quarantena', meaning "forty days", used in the 14th to 15th-century and designating the period that all ships were required to be isolated before passengers and crew could go ashore during the Black Death plague epidemic. (Mattioli A. V., 2020).

Dictionary defines it as "a period, originally 40 days, of detention or isolation imposed upon ships, persons, animals, or plants on arrival at a port or place, when suspected of carrying some infectious or contagious disease'".

In public health practice, "quarantine" refers to the separation of persons (or communities) who have been exposed to an infectious disease. "Isolation", in contrast, applies to the separation of persons who are known to be infected. (Parmet, 2020).

With the obligatory quarantine where people were obliged to stay home, some effects were also felt also in terms of food consumed and dietary changes.

Some studies are conducted in some other countries to evaluate the short term and immediate effects of Covid-19 outbreak on food security, food consumption, dietary changes and physical activities. A study in Iran's Tehran 
province found that consumption pattern was changed during COVID-19 outbreak among participating households. The COVID-19 outbreak led to an increase in households' worrying about providing enough food in Tehran province. (Pakravan-Charvadeh, 2020).

An Italian web-surveyed, which included 3,533 respondents, found that most of the population declared not to have changed its habits (46.1\%), while $16.7 \%$ and $37.2 \%$ felt to have improved them or made them worse. In particular, smoking was reduced during the lockdown and sleep hours have increased. With regards to eating habits, more than half of the participants felt a change in their hunger/satiety perception: 627 (17.7\%) and 1214 (34.4\%) of them had less or more appetite, respectively, (Di Renzo, 2020). Data of this study also shows an increase of homemade recipes (e.g., sweets, pizza and bread), cereals, legumes, white meat and hot beverages consumption, and a decrease of fresh fish, packaging sweets and baked products, delivery food and alcohol intake.

Another study concluded that the frequencies of salt, fat/oil, sweets and fruit juice/squash have decreased during the quarantine. This can be justified by the fact that home-made dishes contain less salt, fat and sugar than the pre-processed ones. (Eftimov, 2020).

On the other hand, the frequencies of stalk vegetables, fruits as vegetables, fruit containing stone, berries and pulses have increased. It was also found that the frequencies of corn/cereals/grain, seafood, citrus fruits, particular vegetables and fruit, herbs and nuts, which present main ingredients of healthy diet (such as the Mediterranean diet) were decreased. (Eftimov, 2020).

Quarantine is an unpleasant experience: with loss of freedom, uncertainty over disease status, and boredom and therefore can affect the health status of individuals. As a result, the potential benefits of mandatory mass quarantine need to be weighed carefully against the possible long-term negative effects on health, i e. cardiovascular risk burden and mental disease. Survey studies on subjects who had been quarantined reported a high prevalence of psychological distress and disorder symptoms. These include emotional disturbance, depression, stress, low mood, irritability, insomnia, and post-traumatic stress. (Mattioli A. V., 2020).

The main consequence of stress, related to quarantine, is a change in lifestyle and nutritional habits. Changes in nutritional habits can be due to: 1 . reduced availability of goods, 2 . limited access to food caused by restricted store opening hours, and 3. switch to unhealthy food to fight stress, depression and anxiety, which induce people to eat sugar-rich food and drink alcohol to feel better. 
This article aims to assess and analyze the immediate impact of Covid-19 on eating habits and dietary changes before and during the quarantine among the population of Tirana

\section{Methodology}

The research methodology is descriptive analysis, where data collected through questionnaires, are afterwards analyzed in Excel and interpreted. The study was conducted between the beginning of March and end of May 2020 in Tirana. Tirana was selected as a study area since, it is the capital of Albania and the most populated city (almost 1 million or about the third of the country population). Data collection took place from the first day of the quarantine along twelve weeks. The questionary was designed in Google form in consultation with experts of the field. The study comprised a structured questionnaire that inquired demographic information (age, gender, education level, marital status, employment status), health conditions information, dietary habits information (number of main meals, number of snacks) as well as differences in several food categories consumption. The study was conducted online due to the strict government regulations, including travel restrictions and social distancing after the Covid-19 outbreak. A total number of 325 respondents have been included in the study.

We were not able to have representation of all classes of society in our sample, due to limitations for internet access. Our sampling approach likely included mainly families with higher education and income, not including those with low education and income, those with no access to internet, etc. To our knowledge, this is the first published paper to assess and analyze the changes in food consumption during the quarantine in Albania, therefore we could not find any published data with which to compare the results.

\section{Result analysis}

During the study we identified the main consumed products of an Albanian consumer and analyzed the changes in the quantity and quality of products consumed before and during the quarantine. As expected, physical distancing and self-isolation strongly impacted citizens' lives, affecting in particular eating habits and everyday behaviors. (Di Renzo, 2020).

Regarding eating habits, about $66.5 \%$ of people confirmed that quarantine has affected the way they eat. While $33.5 \%$ have not seen any major changes in their diets during the pandemic period.

In our modern society, the busy lifestyle imposes people not to consume all the main meals, meanwhile staying at home has led $57 \%$ of them to consume all the main meals. However, $67.4 \%$ of respondents declared to also have consumed more snacks than usually. 
Table 1: Participants' general characteristics:

\begin{tabular}{|l|l|}
\hline General Information & Whole Sample $\mathrm{n}=325$ \\
\hline Gender & \\
\hline Female & 239 \\
\hline Male & 86 \\
\hline Age groups (years) & \\
\hline$<20$ & 78 \\
\hline $20-40$ & 203 \\
\hline $40-60$ & 31 \\
\hline$>60$ & 13 \\
\hline Education & \\
\hline Low level & 9 \\
\hline Middle level & 53 \\
\hline High level & 263 \\
\hline Marital status & \\
\hline Single & 195 \\
\hline Married & 84 \\
\hline Other & 46 \\
\hline Employment & \\
\hline Unemployed & 147 \\
\hline Employed & 160 \\
\hline Self-employed & 18 \\
\hline Health status & \\
\hline With medical condition & 304 \\
\hline without medical condition & 21 \\
\hline & \\
\hline
\end{tabular}

The list of food categories taken into study and differences of consumption level before and during quarantine:

Table 2: Variation of food consumption before and during the confinement

\begin{tabular}{|l|l|l|}
\hline Food category & Same level of consumption $(\mathrm{n})$ & Increased level of consumption (n) \\
\hline Bread & 156 & 169 \\
\hline Dairy & 159 & 166 \\
\hline Fruit & 86 & 239 \\
\hline Vegetables & 169 & 156 \\
\hline Meat & 166 & 159 \\
\hline Sweets & 143 & 182 \\
\hline Fizzy drinks & 247 & 78 \\
\hline Coffee & 218 & 107 \\
\hline Alcohol & 283 & 42 \\
\hline Water & 97 & 228 \\
\hline
\end{tabular}




\section{Interpretation of the results:}

- $52 \%$ of the 325 respondents, have increased the consumption of bread, consuming more white bread. Moreover, $21.5 \%$ of respondents have made their own bread at home, not only because they consider it safer in the time of pandemics, but also as an entertainment.

- In general, Albanian people consume a lot of dairy products. A lot of them prefer to buy these products directly from the farmers. However, because of the lockdown, they bought dairy products directly from the markets. $51 \%$ of people consumed more dairy products during quarantine than before. The most consumed products were milk, yogurt and feta cheese.

- The level of fruit consumption has increased significantly due to the calls made by the health authorities about their role in boosting body's immune response. $73.5 \%$ have consumed more fruit during than before the quarantine. The preferred fruit is orange $(93 \%$ were consuming orange as fruit, juice or smoothie) because of the high level of vitamin C.

- $52 \%$ of respondents said they have increased the level of vegetable consumption. Among the most consumed vegetables have been tomatoes, peppers, and salads. Not only these vegetables are rich in vitamins, especially vitamin $\mathrm{C}$, but as well they are constantly among the most preferred in Albanian cuisine over the time.

- It is noted that $51.1 \%$ of the participants have increased the consumption of meat. About $26 \%$ have consumed red meat, mainly pork, and $20 \%$ chicken, since both are preferred as they are cheaper and easier to digest compared to red meat.

- As we all experienced, quarantine results in boredom, which in turn is associated with a greater energy intake, like chocolates. $56 \%$ of the respondents consumed more sweets during the quarantine. $65.55 \%$ of the total respondents consumed home-made sweets, for the same reasons such as restrictions on movement, entertainment and to idle away the hours. Those foods, mainly rich in simple carbohydrates, can reduce stress as they encourage serotonin production with a positive effect on mood improvement.

- Although carbonated beverages are not quite healthy, their consumption appears to have increased by $24 \%$ during quarantine. Respondents say this was directly related to the increase snack consumption and more time in front of the TV.

- $33 \%$ of the respondents said that they were consuming more caffeine during confinement, meanwhile quarantine did not affect the level of consumed caffeine for $67 \%$ of them. 
- The majority of the respondents $(87 \%)$ did not increase alcohol consumption due to the effect of alcohol in the immune system.

- According to doctors, water is vital for the well functioning of the body and keeping the immune system at an optimal level, therefore, $70 \%$ of the respondents declared to have increased its consumption during confinment.

\section{Conclusion and discussion}

As shown by the results of this study, it is obvious that quarantine has affected every aspect of life, including eating habits and diet. About $66.5 \%$ of people confirmed that quarantine has affected the way they eat, while $33.5 \%$ have not experienced any major changes in their diets during the pandemic period. Staying at home has led $57 \%$ of them to consume all the main meals, and $67.4 \%$ of people have consumed more snacks than usual.

Almost $50 \%$ of the respondents from a total of 325 confirmed that they were consuming more bread, dairy products, meat sweets, vegetables than prior to confinement. Their preferable foods were white bread, milk, chicken, homemade baked sweets and tomatoes. More than $70 \%$ were consuming more fruits, especially orange, coffee and water. Almost $70 \%$ of the respondents were drinking less alcohol and carbonated drinks during confinement than before.

As the results show, people paid special attention to the consumption of healthy food products that help strengthen the immune system, and avoided those products such as sweets or alcohol that prevent or inhibit the fight against Coronavirus disease.

Right before an evitable second lockdown, we must promote healthy diet and physical activity at home that will strengthen our immune system. Global action supporting healthy diets and physical activity is mandatory to encourage people to return to a good lifestyle.

\section{References:}

1. Di Renzo, L., Gualtieri, P., Pivari, F., Soldati, L., Attinà, A., Cinelli, G., Cinelli, G., Leggeri, C., Caparello, G., Barrea, L., Scerbo, F., Esposito, E., \& De Lorenzo, A. (2020). Eating habits and lifestyle changes during COVID-19 lockdown: An Italian survey. Journal of Translational Medicine, 18(1), 229. https://doi.org/10.1186/s12967020-02399-5

2. Pakravan-Charvadeh, M. R., Mohammadi-Nasrabadi, F., Gholamrezai, S., Vatanparast, H., Flora, C., \& Nabavi-Pelesaraei, A. (2020). The short-term effects of COVID-19 outbreak on dietary diversity and food security status of Iranian households (A case study 
in Tehran province). Journal of Cleaner Production, 124537. https://doi.org/10.1016/j.jclepro.2020.124537

3. Mediouni, M., Madiouni, R., \& Kaczor-Urbanowicz, K. E. (2020). COVID-19: How the quarantine could lead to the depreobesity. Obesity Medicine, 19, 100255.

https://doi.org/10.1016/j.obmed.2020.100255

4. Ripon, R. K., Mim, S. S., Puente, A. E., Hossain, S., Babor, M. M. H., Sohan, S. A., \& Islam, N. (2020). COVID-19: psychological effects on a COVID-19 quarantined population in Bangladesh. Heliyon, 6(11), e05481. https://doi.org/10.1016/j.heliyon.2020.e05481

5. Duda-Chodak, A., Lukasiewicz, M., Zięć, G., Florkiewicz, A., \& Filipiak-Florkiewicz, A. (2020). Covid-19 pandemic and food: Present knowledge, risks, consumers fears and safety. In Trends in Food Science and Technology (Vol. 105, pp. 145-160). Elsevier Ltd. https://doi.org/10.1016/j.tifs.2020.08.020

6. Zakay-Rones, Z., Thom, E., Wollan, T., \& Wadstein, J. (2004). Randomized Study of the Efficacy and Safety of Oral Elderberry Extract in the Treatment of Influenza A and B Virus Infections. Journal of International Medical Research, 32(2), 132-140. https://doi.org/10.1177/147323000403200205

7. Eftimov, T., Popovski, G., Petković, M., Seljak, B. K., \& Kocev, D. (2020). COVID-19 pandemic changes the food consumption patterns. In Trends in Food Science and Technology (Vol. 104, pp. 268-272). Elsevier Ltd. https://doi.org/10.1016/j.tifs.2020.08.017

8. Mattioli, A. V., Sciomer, S., Cocchi, C., Maffei, S., \& Gallina, S. (2020). Quarantine during COVID-19 outbreak: Changes in diet and physical activity increase the risk of cardiovascular disease. In Nutrition, Metabolism and Cardiovascular Diseases (Vol. 30, Issue 9, pp. 1409-1417). Elsevier B.V.

https://doi.org/10.1016/j.numecd.2020.05.020

9. Parmet, W. E., \& Sinha, M. S. (2020). Covid-19 - The Law and Limits of Quarantine. New England Journal of Medicine, 382(15), e28. https://doi.org/10.1056/nejmp2004211

10. Are Diets During Coronavirus Changing for the Better? https://time.com/5827315/coronavirus-diet/

11. Eating habits during the COVID-19 confinement in the UK. https://docs.google.com/forms/d/e/1FAIpQLSf4XbJRik9dm86e58K Qx6qHjbe3nz82ppDluzE4hZPPyNQXww/viewform

12. Making Nutrition a Priority During the Pandemic | Psychiatry | Michigan Medicine | University of Michigan. 
https://medicine.umich.edu/dept/psychiatry/michigan-psychiatryresources-covid-19/your-lifestyle/making-nutrition-priority-duringpandemic

13. How eating habits are shifting.

https://www.supermarketperimeter.com/articles/5549-la-breasurveys-consumers-about-quarantine-bread-eating-habits 